\title{
Spray Breakup and Structure of Spray Flames for Low-volatility Wet Fuels
}

José E. Madero ${ }^{\text {a }}$, Richard L. Axelbaum ${ }^{\text {b** }}$

${ }^{\mathrm{a}}$ Department of Mechanical Engineering and Materials Science, Washington University in St. Louis

${ }^{\mathrm{b}}$ Department of Energy, Environmental, and Chemical Engineering, Washington University in St. Louis

* Corresponding author.

Mailing Address:

One Brookings Drive, Box 1180, Brauer Hall, Room 3006, St. Louis, MO 63130, USA

Tel: 01-314-935-7560 Fax: 01-314-935-7211

Email: axelbaum@wustl.edu (R.L. Axelbaum)

\section{Abstract}

Studies of high-water-content fuels (a.k.a, wet fuels) have demonstrated that, under proper conditions, stable combustion can be achieved at very high water concentrations. Stable spray flames of wet fuels have been attained with fuel/water mixtures having stoichiometric adiabatic flame temperatures as low as $251{ }^{\circ} \mathrm{C}$. In this study we investigate low-volatility wet fuels, using glycerol as the fuel, and ethanol as a stabilization additive. This study expands on previous work by determining the minimum amount of ethanol that needs to be added to a glycerol/water mixture to produce a stable flame and by investigating the spray dynamics and structure for these fuels, to delineate the mechanism of ignition and to understand how ethanol alters the vaporization behavior, droplet breakup, and spray dynamics. Detailed 2-D velocity, Sauter mean diameter (SMD), 2-D flux, and number concentration measurements were performed with a Phase Doppler Particle Analyzer (PDPA) in sprays of three fuel/water mixtures: a) 30\% glycerol/70\% water, b) 30\% glycerol/10\% ethanol/60\% water, and c) the same mixture as b) but in a combusting spray. All percentages are by weight. Results show that the addition of ethanol to the glycerol/water mixture turns the hollow cone spray pattern into a narrow full cone pattern, leading to recirculation of fine droplets in the region just downstream of the nozzle, which is essential to ignition. The high concentration of fine droplets, along with the high vapor pressure and high activity coefficient of ethanol leads to extremely rapid vaporization of ethanol in the inner recirculation zone. The combustion of the ethanol raises the temperature in this region, while the swirling flow brings heat 
upstream towards the nozzle, further enhancing stability. These results explain why the addition $10 \%$ ethanol can lead to robust flames of glycerol/water mixtures that might not be expected to yield stable combustion.

\section{Keywords}

Wet fuels

Preferential vaporization

Spray flame

Ethanol

Glycerol

Multicomponent fuels

\section{Introduction}

Despite the low calorific value of high-water-content (wet) fuels, direct combustion can be used to extract energy from fuels that might otherwise be of limited value. Furthermore, such an approach would have the advantage of avoiding the energy-intensive dewatering processes. For example, dewatering can account for as much as $37 \%$ of the energy content in bioethanol [1] and 20-30\% of the total production cost of biofuel from microalgae [2]. In addition, since the products of combustion would contain a considerable amount of water, a high-temperature and high-pressure stream of steam could be produced in one step rather than the traditional two-step approach involving a combustor and boiler. Thus, a simple and compact system could be utilized for applications that require high temperature steam, such as in the oil industry, where steam is injected into oil sands to extract liquid fuels [3]. Direct combustion of wet fuels also shows promise for energy generation. Since the steam temperature would no longer be limited by heat transfer through the boiler tubes, higher temperatures than those allowed by even the most advanced boiler materials could be achieved and this can lead to a considerable increase in efficiency [4,5]. If used in pressurized systems, the latent heat used to evaporate the water could be recovered and utilized, and if oxygen is used as the oxidizer, this would allow for efficient carbon capture after the steam is condensed out [6-8].

Previous studies have demonstrated the feasibility of combusting fuels containing high water content. Breaux and Acharya obtained a stable flame for 59\% ethanol/41\% water mixtures in a swirl-stabilized burner 
[9]. Stable operation in HCCI engines was demonstrated with ethanol containing up to $46 \%$ water by Mack et al [10] and Saxena et al [11]. Yi and Axelbaum attained self-sustained combustion of ethanol with as little as 25\% ethanol when burning in air and $10 \%$ ethanol when burning in $60 \% \mathrm{O}_{2}$ in a swirl stabilized burner [12].

\subsection{Preferential Vaporization of Wet Fuels}

The stoichiometric adiabatic temperatures of wet fuels can be quite low. For example, for a 10\% ethanol/90\% water mixture burning in $60 \% \mathrm{O}_{2}$ flame, it is $251{ }^{\circ} \mathrm{C}$ and thus, these conditions might not be expected to lead to stable burning [12]. During spray combustion, the partial pressures of fuel and water at the droplet surface can be estimated from Raoult's Law [13]. Furthermore, when an alcohol is mixed with water, a non-ideal solution is formed, leading to an activity coefficient that can be much greater than unity. A high activity coefficient can dramatically increase the extent of preferential vaporization by increasing the equilibrium fraction of fuel in the vapor phase [14]. Also, the activity coefficient of alcohol in water increases as the water fraction increases and can be as high as 5 for a mixture of $10 \%$ ethanol/90\% water, implying that the vapor pressure at the surface is five times higher than it would be for an ideal mixture at the same temperature. This increase in activity coefficient can offset the reduction in fuel vaporization rate that one might expect when the fuel is diluted, and this phenomenon was found to allow for stable combustion of very dilute ethanol/water mixtures as described above [12].

In the case of fuels with low volatility relative to water, the opposite behavior occurs, wherein the water can vaporize preferentially over the fuel. Yi and Axelbaum studied the oxy-combustion of glycerol/water mixtures [15]. Glycerol is a by-product of biodiesel production, with limited commercial value. Typically, it takes between 0.3 to 1 gallons of water to separate the glycerol from the biodiesel, and 10 to $20 \%$ of the total volume of biodiesel produced is made up of glycerol [16]. As biodiesel production increases, finding uses for this by-product is becoming important in order to improve the economic viability of biodiesel. One option is to use it as a fuel for process heating or electricity generation. Direct combustion of glycerol has been achieved by heating the fuel to reduce the kinematic viscosity of the fuel so that it can be atomized, and by heating the oxidizer to overcome the high ignition temperature of glycerol [17,18]. Jian and Agrawal were able to achieve 
stable combustion of neat glycerol without preheating the fuel by using a novel flow-blurring liquid fuel injector in an insulated combustor [19].

Glycerol has a high boiling point $\left(290^{\circ} \mathrm{C}\right)$, a low vapor pressure, and an activity coefficient of nearly unity when mixed with water. Thus, when glycerol is used as a wet fuel, water vaporizes preferentially over the fuel, making it difficult to burn, and, unlike when burning pure glycerol, preheating the fuel does not aid ignition. The addition of water does, however, lower the kinematic viscosity, so atomization is not an issue as it is with neat glycerol.

In Ref. [15], stable glycerol/water flames were obtained with $60 \%$ glycerol/40\% water when burned in pure oxygen, but the flame was lifted from the nozzle despite the fact that the stoichiometric adiabatic flame temperature of this flame is $2602{ }^{\circ} \mathrm{C}$. To enhance the stability of the glycerol/water mixtures, a high volatility fuel was added to the mixture, allowing attached, robust flames to be obtained for $30 \%$ glycerol/10\% ethanol/60\% water mixtures in pure oxygen. That work concluded that the addition of ethanol increased the fuel vapor pressure near the nozzle, which allowed for ignition and stable combustion.

The present study expands on this previous work to better understand the mechanism by which ethanol addition to glycerol/water mixtures improves flame ignitability and stability. This is accomplished by investigating spray breakup and spray structure of glycerol/water and glycerol/ethanol/water mixtures. The former mixture represents the reference low-volatility wet fuel and the latter represents a low-volatility wet fuel wherein a high-volatility fuel is added to improve flame ignitability. Since the objective is to understand how the addition of small amounts of ethanol turn a non-ignitable mixture into one that yields a robust flame, a cold glycerol/water spray was studied in detail even though the spray dynamics are very different from that of a combusting spray, as this condition serves as the state that needs to be ignited before a stable flame can be reached. Breakup of the sprays was studied using high-speed video, and measurements of the 2-D velocity, Sauter mean diameter (SMD), 2-D flux, and number concentration were obtained, both with and without combustion, using a Phase Doppler Particle Analyzer (PDPA).

Numerous studies, both fundamental [20-23] and experimental [24-29], have shown that altering fluid properties such as surface tension, viscosity and specific gravity can affect both the spray breakup process and 
the spray cone angle, which in turn can affect the droplet size and velocity distributions. Since glycerol/water mixtures are inherently unstable, even minor changes in the spray characteristics can impact the ignition and stability of such systems. Therefore, an understanding of the effect that the additive has on spray breakup and structure, in conjunction with the effect it has on preferential vaporization, is needed before the combustion of wet fuels can be fully understood and utilized.

\section{Experimental Setup}

The swirl-stabilized burner setup is the same as in Ref. [15] and a schematic is shown in Fig. 1. A pressure-swirl hollow-cone nozzle with a nominal $30^{\circ}$ angle was used (Monarch Nozzles 0.5NS30). The nozzle has a $14 \mathrm{~mm}$ diameter and a $0.2 \mathrm{~mm}$ discharge orifice. The pressure drop across the nozzle was held constant at $6.8 \mathrm{~atm}$. The oxidizer flow was controlled via mass flow controllers and injected through $6.35 \mathrm{~mm}$ inlets. Only the swirl inlets were utilized, and both fuel and oxidizer were introduced at $25^{\circ} \mathrm{C}$ for all cases studied. Ignition was achieved with the use of an ethane torch inserted through the ignition port and placed downstream of the nozzle. The torch was removed once a flame attached to the nozzle could be observed, or after a few minutes if no ignition was possible.

To determine the minimum amount of ethanol that needs to be added to a glycerol/water mixture to produce a stable flame, different glycerol/water mixtures were used and then ethanol was added in $2.5 \%$ increments until it was possible to ignite the system and obtain a stable flame. The three cases studied in detail are summarized in Table 1. The fuel tank was placed on a weighing scale and flow rate was calculated gravimetrically. Viscosity and surface tension were obtained using the ASTM D 445.c and ASTM D 971.b methods, respectively. No oxidizer flow was present for the cold spray measurements for the following reasons: First, the goal was to determine how using an additive in the mixture affects the spray formation and liquid flow dynamics, independently of the oxidizer flow and the geometry of the burner. Also, since the oxidizer is injected tangentially to the walls, when running a cold spray with oxidizer flow, the walls are quickly covered in liquid, which disrupts the laser diagnostics. Measurements for a combusting 30\% glycerol/70\% water mixture were not performed since it is not possible to ignite this mixture. 
The PDPA system used is a two-component TSI system operating in forward-scatter mode at a $30^{\circ}$ offaxis angle. The transmitting optics have a focal length of $363 \mathrm{~mm}$, generating a measurement volume with a 90 $\mu \mathrm{m}$ beam waist and 24 fringes with a $3.7 \mu \mathrm{m}$ separation. The receiving optics have a focal length of $300 \mathrm{~mm}$. At each location, $10^{5}$ samples were acquired. Based on the optical setup employed, the velocity and droplet diameter measurements have a $\sim 2 \%$ and a $\sim 4 \%$ margin of error, respectively. Spray breakup was recorded using a high-speed camera (nac Memrecam HX-7) at 60,000 fps with a shutter speed of $1.9 \mu \mathrm{s}$.

\section{Results}

A stability map showing the minimum amount of ethanol that must be added to a glycerol/water mixture to produce a stable flame is shown in Fig. 2. The addition of as little as $2.5 \%$ ethanol to a $50 \%$ glycerol/50\% water mixture is needed to obtain a stable flame. In the case of $30 \%$ glycerol/70\% water, a minimum of $8 \%$ ethanol is required for ignition to be achieved. As glycerol concentration increases, less ethanol is required to obtain a stable flame, until $60 \%$ glycerol $/ 40 \%$ water, where it is possible to stabilize the flame without the additive. Similarly, no mixture requires more than $15 \%$ ethanol, since the $15 \%$ ethanol/85\% water system yields a stable flame.

Figure 3 shows images of the breakup of the G30 and the G30E10 sprays. The addition of $10 \%$ ethanol to the mixture more than doubles the breakup length of the conical liquid sheet, and the spray cone angle also decreases. To understand the differences in breakup, the discharge coefficient, $C_{\mathrm{D}}$, Reynolds number, $R e$, Weber number, We, and Ohnesorge number, $\mathrm{Oh}$, for the two mixtures were calculated and are summarized in Table 2. Here $C_{D}=\frac{Q}{A\left(\frac{2 \Delta P}{\rho}\right)^{0.5}}$, where $Q$ is the liquid volume flow rate, $A$ is the nozzle's orifice cross-sectional area and $\Delta P$ is the pressure difference across the nozzle; $R e=\frac{\rho d U_{s}}{\mu}$, where $d$ is the orifice diameter, $U_{s}=\sqrt{\frac{2 \Delta P}{\rho}}$ and all properties are liquid properties; $W e=\frac{\rho_{g} Q^{2} d}{\sigma A^{2}}$ where $\rho_{\mathrm{g}}$ is the oxidizer density; and $O h=\frac{v \rho}{(\rho \sigma d)^{0.5}}$ ).

Radcliffe [30] studied the discharge coefficient as a function of Reynolds number and found that at $R e>$ 2000, $C_{\mathrm{D}}$ is independent of Reynolds number. Chung and Presser [31] determined that a lower surface tension leads to a higher discharge coefficient, which could explain the small increase in $C_{\mathrm{D}}$ observed for the G30E10 case. Nonetheless, this small change in $C_{\mathrm{D}}$ does not affect the system in an appreciable manner. In the same 
work, Chung and Presser found that for $R e>2000$, both Reynolds and Ohnesorge number influence the breakup length, with enhanced liquid inertia (higher $R e$ ) reducing breakup length, and increased surface tension (lower $O h$ and $W e$ ) enlarging breakup length. Considering the cases studied, it is possible to conclude that the increase in breakup length for G30E10 is viscosity-driven, which leads to a lower Reynolds number and therefore a longer breakup length. While this mixture also has a lower surface tension, the results suggest that this is not the dominant parameter in the resulting breakup length. The observed reduction in spray angle for G30E10 can also be attributed to the decrease in $R e$ and is consistent with the findings of Fan et al [28] and Davanlou et al [29].

Figure 4 compares the droplet axial and radial velocity profiles, and SMD for the G30 and the G30E10 sprays. In the G30 case, radial components of velocity have small negative values close to the centerline in the near-nozzle region but not downstream (Fig. 4b.) In comparison, the radial components of velocity in the G30E10 case have high negative values close to the centerline at an axial distance $5 \mathrm{~mm}$ away from the nozzle (Fig. 4e.) As shown in Fig. 4c, the SMD for G30 is smallest near the centerline at all axial locations and moves outward away from the nozzle while the peak in SMD also increases. For G30E10, the SMD is also smallest near the centerline close to the nozzle, but away from the nozzle becomes almost constant radially (Fig. 4f.) In the near-nozzle region, the maximum SMD observed for G30E10 is higher than that for G30 due to the delayed breakup, as observed in Fig. 3, but becomes slightly smaller than that of G30 downstream, once breakup is completed ( $~ 8 \mathrm{~mm}$ away from nozzle,) which can be attributed to the lower surface tension of the G30E10 mixture.

In Fig. 5 the droplet velocity, volume flux and number concentration are compared for both fuels. For G30, the maximum flux region coincides with the edge of the spray cone and moves outward (Fig. 5a.) For G30E10 the maximum flux region is also close to the edge of the spray in the near-nozzle region, but downstream moves towards the centerline (Fig. 5c.) The velocity field shows strong recirculation in the nearnozzle region where the conical liquid sheet is still present, which creates a high concentration of droplets that does not exist in the G30 case ( $c f$. Fig. 5b with Fig. 5d.) Farther from the nozzle the droplets in the G30E10 case move in an almost completely axial direction in the central region, unlike in the G30 case. Based on flux, the 
G30E10 spray does not show a hollow cone pattern even though it originates as a hollow cone; instead the spray is more akin to a full cone with a narrow spray angle and with similarly sized droplets throughout.

Figure 6 shows the breakup of the G30E10c case. Compared to the cold spray, the liquid sheet breakup length is much shorter and the spray cone wider for the combustion case since, as temperature increases, both the viscosity and surface tension of the mixture decrease. The decrease in breakup length could also be attributed to the thinning of the liquid sheet due to vaporization, which causes perturbations to disrupt the sheet more easily, so that droplet formation occurs sooner [32].

Figures $7 \mathrm{a} \& \mathrm{~b}$ show the axial and radial velocity profiles for the G30E10c case. No droplets can be detected near the centerline and the radial components of velocity that could be measured are positive in all locations. As shown in Fig. 7c, the SMD is largest at the core of the spray jet and quickly decreases towards both sides. The maximum SMD increases downstream due to full vaporization of the smaller droplets. The spray angle for G30E10c is wider than for both cold spray cases.

Figure 8 shows the velocity field of the spray and the gas phase for the G30E10c case. In the combusting case, the spray follows a uniform, hollow-cone pattern, unlike in the cold spray of the same mixture. This is explained by the earlier liquid sheet breakup and rapid vaporization of small droplets, so that only large droplets with high momentum remain. The gas-phase velocity field shows two distinct regions: one of high axial velocity components near the combustor walls due to the fact that the oxidizer is injected into the combustor tangential to the walls, and a centerline region with reverse flow, characterized by high negative velocity components.

\section{Discussion}

In a swirl-stabilized burner, an inner-recirculation zone exists due to the toroidal vortex formed [33,34], which recirculates heat and radicals towards the jet, supporting combustion. For stable combustion to occur, sufficient fuel needs to vaporize from the jet in the inner recirculation zone [35]. Previous studies have shown that for wet fuels, preferential vaporization is essential for flame stability $[12,14]$. For fuels such as ethanol, which have high volatility relative to water, it is possible to obtain stable flames at very low fuel concentrations (ethanol/water flames with fuel concentrations as low as $20 \%$ burn steadily in air). This occurs because the fuel 
vaporizes preferentially over the water, creating a vapor near the nozzle with a fuel concentration that is much higher than that of the liquid phase, such that a stable flame can exist. If a fuel with a lower relative volatility such as glycerol is used, water vaporizes preferentially over the fuel, creating a water-rich vapor, which reduces fuel concentration, absorbs heat, and inhibits ignition and stabilization. In a previous study, a self-sustained flame could only be obtained with $60 \%$ glycerol in pure oxygen, but even then the flame was lifted from the nozzle. That study also showed that adding $10 \%$ ethanol to the glycerol/water mixture yielded stable flames [15]. In that work, the interpretation of why ethanol stabilized the flame was based strictly on the fact that ethanol had strong preferential vaporization, particularly with the high activity coefficient associated with ethanol/water mixtures. In this study we find that not only does the ethanol change the rate of fuel vaporization due to its volatility, but it also affects the spray breakup and dynamics in a way that positively affects flame stabilization.

\subsection{Flame ignition and stabilization}

Beginning with the cold sprays of the G30 and the G30E10 mixtures, it is clear that the addition of ethanol alters the spray dynamics. First, it causes a delay in the liquid sheet breakup, which creates a void in the region inside the liquid sheet cone, where recirculation transports smaller droplets. These droplets vaporize rapidly, releasing fuel vapor which mixes with the oxidizer present in the region. Upon ignition, the combustion of these droplets releases enough heat to trigger distillation-like vaporization of the ethanol in the system, as observed in Ref. [12]. Once ethanol vaporizes and burns, enough heat has been released to fully vaporize the water and glycerol in the system, and the swirling flow transports hot reaction products towards the nozzle, further enhancing flame stability. As shown in Ref. [15], the maximum measured temperature in the system $\left(\sim 1750^{\circ} \mathrm{C}\right)$ occurs in the region just downstream of the nozzle, the same region where the high concentration of small droplets initially exists. Once the system is ignited, the increasing temperature near the nozzle causes the surface tension and viscosity of the fluid leaving the nozzle to decrease and the liquid sheet to thin, resulting in faster breakup, increased spray angle, and smaller droplet size. The wider spray angle allows an inner and outer flame front to form while the smaller SMD enhances vaporization. The result is a very robust flame despite the 
high water content of the mixture and the fact that the majority of the fuel has a relative low volatility compared to water.

\section{Conclusion}

In this study, the spray breakup and structure of a glycerol/water mixture and an ethanol/glycerol/water mixture were studied to determine how the use of ethanol as an additive for low-volatility wet fuels impacts the spray characteristics and flame ignition and stability. It was found that the addition of ethanol to a glycerol/water mixture delayed the onset of the liquid-sheet breakup, turning the hollow-cone spray pattern into a narrow full-cone pattern. While a hollow-cone spray pattern generally enhances vaporization, in the case of wet fuels -which are inherently unstable- the generation of the recirculation region downstream of the nozzle is essential to ignitability, as the high concentration of fine droplets transported back to the nozzle by recirculation yields rapid heat release near the nozzle. This heat release triggers the rapid vaporization of the higher volatility fuel component, which vaporizes preferentially over water. The high activity coefficient of alcohol in water further enhances the rate of vaporization of the ethanol. The combustion of ethanol acts to stabilize the system, while the swirling flow brings heat upstream towards the nozzle, further enhancing stability. Once the system stabilizes, the spray turns into a wide hollow cone, and a strong stable attached flame is observed. These results explain the somewhat unexpected results of Ref. [15] that the addition of $10 \%$ ethanol can lead to robust flames of glycerol/water mixtures.

In summary, ethanol affects the ignition and stability of the glycerol/water mixture in three ways: First, as delineated in this work, the addition of ethanol affects the spray breakup and dynamics, leading to an initial concentration of very fine droplets in the critical central region of the spray nozzle, 2) the vapor pressure of ethanol is high and 3) the activity coefficient of ethanol in water is very high, leading to extremely high fuel volatility for these mixtures. The result of this is that the ethanol evaporates rapidly in the critical vicinity for ignition.

\section{Acknowledgments}

This work was supported by the U.S. National Science Foundation (NSF) (grant number 1337008) and the Israel Ministry of Defense. 


\section{References}

[1] J. Martinez-Frias, S.M. Aceves, D.L. Flowers, Improving ethanol life cycle energy efficiency by direct utilization of wet ethanol in HCCI engines, J. Energy Resour. Technol. - Tran. ASME 129 (2007) 332-337.

[2] L. Gouveia, Microalgae as a Feedstock for Biofuels, Springer, 2011.

[3] J.J. Sheng, Modern Chemical Enhanced Oil Recovery - Theory and Practice, Gulf Professional Publishing, Houston, TX, 2011.

[4] R.E. Anderson, G. Baxter, Development of a Unique Gas Generator for a Non-polluting Power Plant, California Energy Commission Grant \# 99-20 (2002).

[5] R. Anderson, F. Viteri, R. Hollis, A. Keating, J. Shipper, G. Merrill, C. Schillig, S. Shinde, J. Downs, D. Davies, M. Harris, Oxy-Fuel Gas Turbine, Gas Generator and Reheat Combustor Technology Development and Demonstration, ASME Turbo Expo 3 (2010) 733-743.

[6] A. Gopan, B.M. Kumfer, J. Phillips, D. Thimsen, R. Smith, R.L. Axelbaum, Process design and performance analysis of a Staged, Pressurized Oxy-Combustion (SPOC) power plant for carbon capture, Appl. Energy 125 (2014) 179-188.

[7] H. Hagi, M. Nemer, Y. Le Moullec, C. Bouallou, Towards Second Generation Oxy-pulverized Coal Power Plants: Energy Penalty Reduction Potential of Pressurized Oxy-combustion Systems, Energy Procedia 63 (2014) 431-439.

[8] A. Gopan, B.M. Kumfer, R.L. Axelbaum, Effect of operating pressure and fuel moisture on net plant efficiency of a staged, pressurized oxy-combustion power plant, Int. J. Greenh. Gas Control 39 (2015) 390-396. [9] B.B. Breaux, S. Acharya, The effect of elevated water content on swirl-stabilized ethanol/air flames, Fuel 105 (2013) 90-102.

[10] J.H. Mack, S.M. Aceves, R.W. Dibble, Demonstrating direct use of wet ethanol in a homogeneous charge compression ignition (HCCI) engine, Energy 34 (2009) 782-787.

[11] S. Saxena, S. Schneider, S. Aceves, R. Dibble, Wet ethanol in HCCI engines with exhaust heat recovery to improve the energy balance of ethanol fuels, Appl. Energy 98 (2012) 448-457. 
[12] F. Yi, R.L. Axelbaum, Stability of spray combustion for water/alcohols mixtures in oxygen-enriched air, Proc. Combust. Inst. 34 (2013) 1697-1704.

[13] C.K. Law, Multicomponent droplet combustion with rapid internal mixing, Combust. Flame 26 (1976) 219-233.

[14] F. Yi, R.L. Axelbaum, Utilizing preferential vaporization to enhance the stability of spray combustion for high water content fuels, Combust. Flame 161 (2014) 2008-2014.

[15] F. Yi, R.L. Axelbaum, Oxy-combustion of Low-Volatility Liquid Fuel with High Water Content, Energy Fuels 29 (2015) 1137-1142.

[16] C.A.G. Quispe, C.J.R. Coronado, J.A. Carvalho Jr., Glycerol: Production, consumption, prices, characterization and new trends in combustion, Renew. Sust. Energ. Rev. 27 (2013) 475-493.

[17] M.D. Bohon, B.A. Metzger, W.P. Linak, C.J. King, W.L. Roberts, Glycerol combustion and emissions, Proc. Combust. Inst. 33 (2011) 2717-2724.

[18] S.A. Steinmetz, J.S. Herrington, C.K. Winterrowd, W.L. Roberts, J.O.L. Wendt, W.P. Linak, S.A. Steinmetz, J.S. Herrington, C.K. Winterrowd, W.L. Roberts, J.O.L. Wendt, W.P. Linak, Proc. Combust. Inst. 34 (2013) 2749-2757.

[19] L. Jiang, A.K. Agrawal, Combustion of straight glycerol with/without methane using a fuel-flexible, lowemissions burner, Fuel 136 (2014) 177-184.

[20] R. Reitz, F.V. Bracco, Mechanism of atomization of a liquid jet, Phys. Fluids 25 (1982) 1730-1742.

[21] S.P. Lin, R.D. Reitz, Drop and spray formation from a liquid jet, Annu. Rev. Fluid Mech. 30 (1998) 85105.

[22] J.C. Lasheras, E. Villermaux, E.J. Hopfinger, Break-up and atomization of a round water jet by a highspeed annular air jet, J. Fluid Mech. 357 (1998) 351-379.

[23] W.A. Sirignano, C. Mehring, Review of theory of distortion and disintegration of liquid streams, Prog. Energy Combust. Sci. 26 (2000) 609-655. 
[24] S.H. Park, H.J. Kim, H.K. Suh, C.S. Lee, Experimental and numerical analysis of spray-atomization characteristics of biodiesel fuel in various fuel and ambient temperatures conditions, Int. J. Heat Fluid Flow 30 (2009) 960-970.

[25] H.J. Kim, H.K. Suh, S.H. Park, C.S. Lee, An experimental and numerical investigation of atomization characteristics of biodiesel, dimethyl ether, and biodiesel-ethanol blended fuel, Energy Fuels 22 (2008) 20912098.

[26] R. Payri, B. Tormos, F.J. Salvado, L. Araneo, Spray droplet velocity characterization for convergent nozzles with three different diameters, Fuel 87 (2008) 3176-3182.

[27] A. Tratnig, G. Brenn, T. Strixner, P. Fankhauser, N. Laubacher, M. Stranzinger, Characterization of spray formation from emulsions by pressure-swirl atomizers for spray drying, J. Food Eng. 95 (2009) 126-134.

[28] Y. Fan, N. Hashimoto, H. Nishida, Y. Ozawa, Spray characterization of an air-assist pressure-swirl atomizer injecting high-viscosity Jatropha oils, Fuel 121 (2014) 271-283.

[29] A. Davanlou, J.D. Lee, S. Basu, R. Kumar, A. Davanlou, J.D. Lee, S. Basu, R. Kumar, Chem. Eng. Sci. 131 (2015) 243-255.

[30] A. Radcliffe, The performance of a type of swirl atomizer, P. I. Mech. Eng. 169 (1955) 93-106.

[31] I.P. Chung, C. Presser, Fluid property effects on sheet disintegration of a simplex pressure-swirl atomizer, J. Propulsion 17 (2001) 212-216.

[32] H.C. Rodrigues, M.J. Tummers, E. H. van Veen, D.J.E.M. Roekaerts, H.C. Rodrigues, M.J. Tummers, E. H. van Veen, D.J.E.M. Roekaerts, Combust. Flame 162 (2015) 759-773.

[33] R.H. Chen, J.F. Driscoll, J. Kelly, M. Namazian, R. Schefer, A comparison of bluff-body and swirlstabilized flames, Combust. Sci. Technol. 71 (4-6) (1990) 197-217.

[34] D. Sequera, A.K. Agrawal, S.K. Spear, D.T. Daly, Combustion performance of liquid biofuels in a swirlstabilized burner, J. Eng. Gas Turbines Power 130 (3) (2008) 032810.

[35] A.K. Gupta, D.G. Lilley, N. Syred, Swirl Flows; Abacus Press, Tunbridge Wells, U.K., 1984. 
Figure 1. Description of swirl-stabilized burner.

Figure 2. Stability map of the glycerol/ethanol/water system. A circle represents a stable flame and an x mark represents a condition where a flame could not be established.

Figure 3. Spray breakup of 30\% glycerol (left) and 30\% glycerol/10\% ethanol (right).

Figure 4. Measured (a) axial and (b) radial droplet velocity components and (c) SMD for 30\% glycerol and (d,e,f) $30 \%$ glycerol $/ 10 \%$ ethanol.

Figure 5. (a) Velocity field and flux, and (b) number concentration for $30 \%$ glycerol and (c,d) $30 \%$ glycerol/10\% ethanol.

Figure 6. Breakup of the $30 \%$ glycerol/10\% ethanol combusting spray.

Figure 7. (a) Axial and (b) radial velocity components and (c) SMD for the $30 \%$ glycerol/10\% ethanol combusting case.

Figure 8 . Velocity field of spray and gas phase for the $30 \%$ glycerol/10\% ethanol combusting case.

Table 1: Cases studied

Table 2: Mixtures' dimensionless parameters 


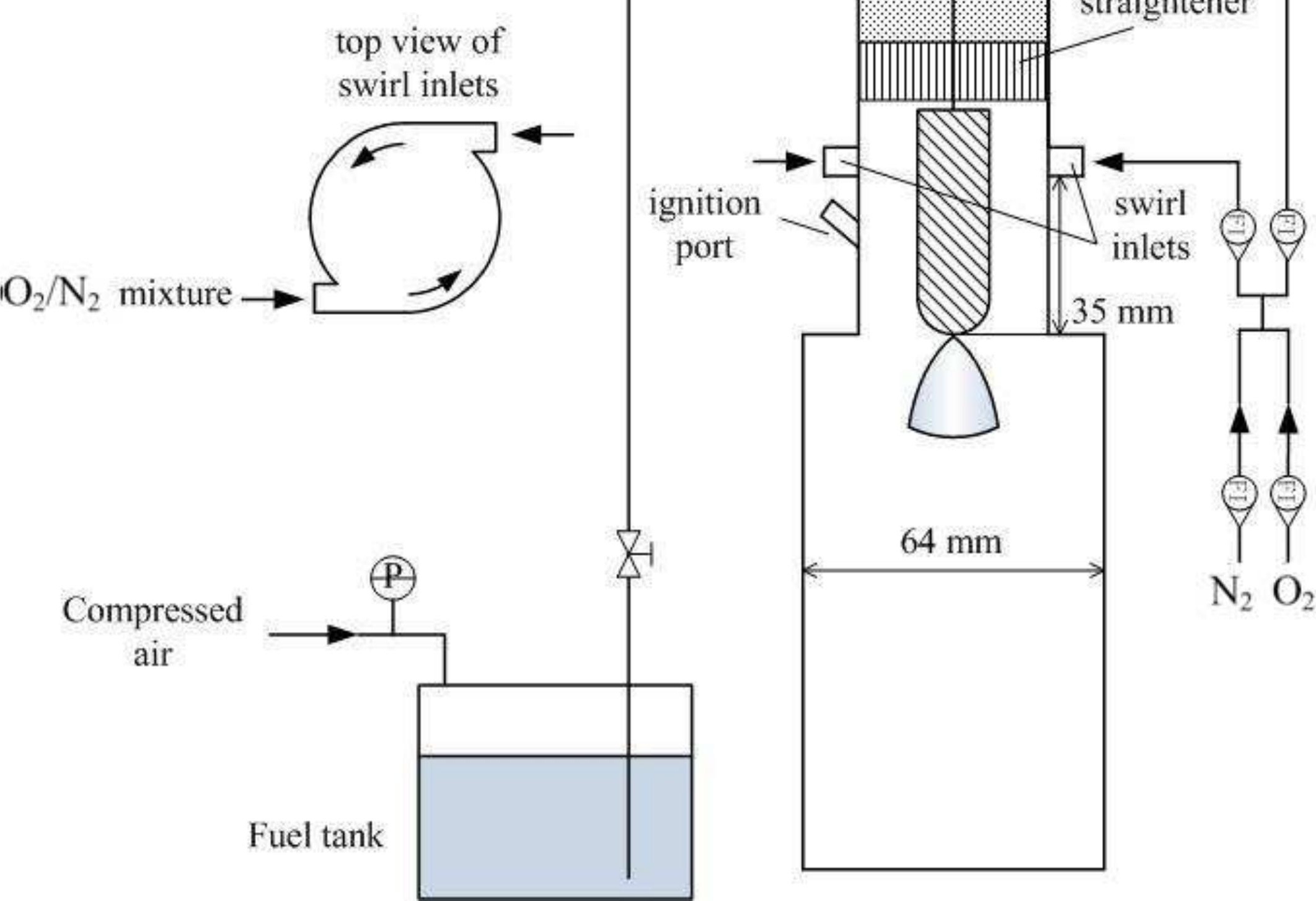




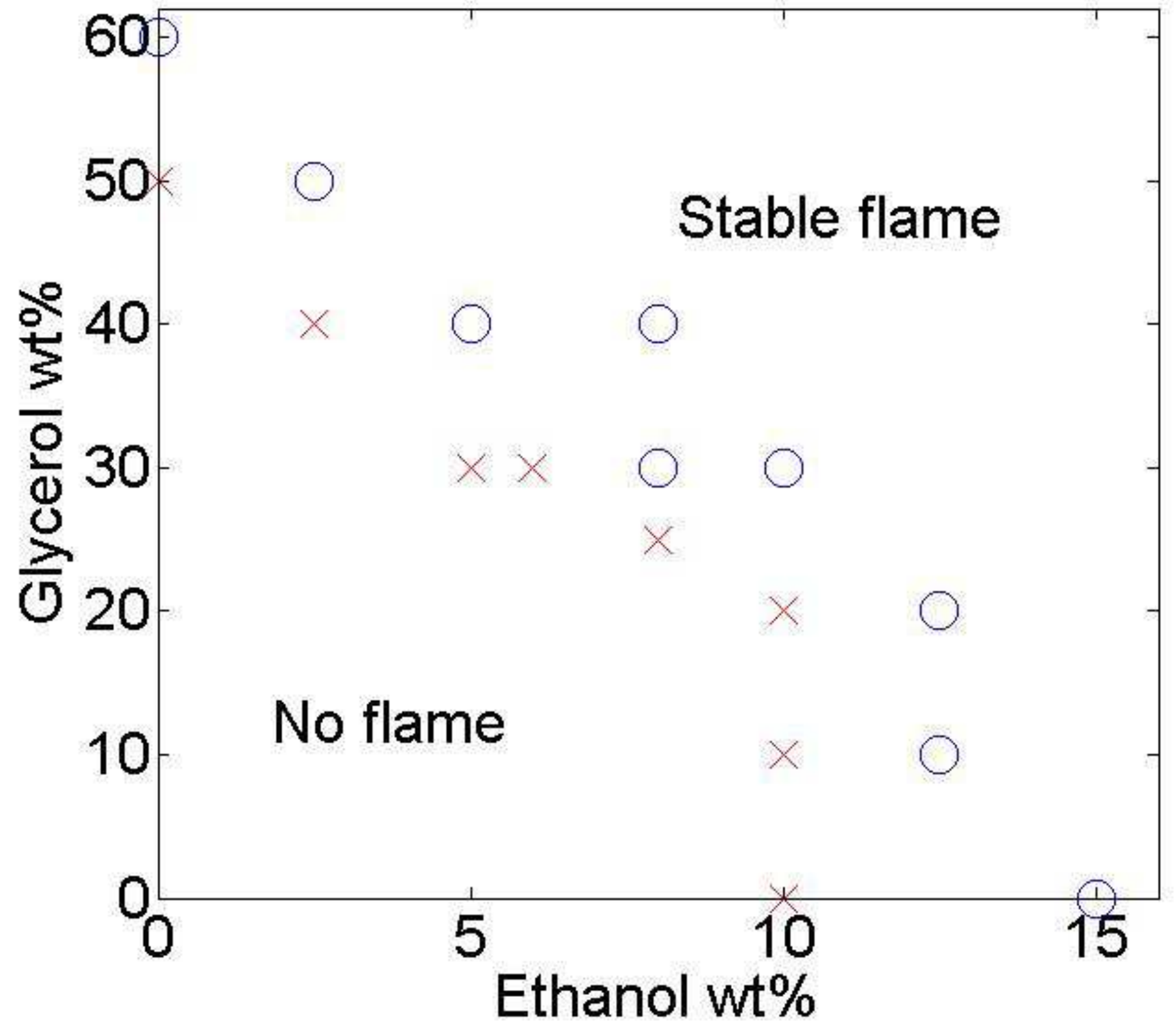





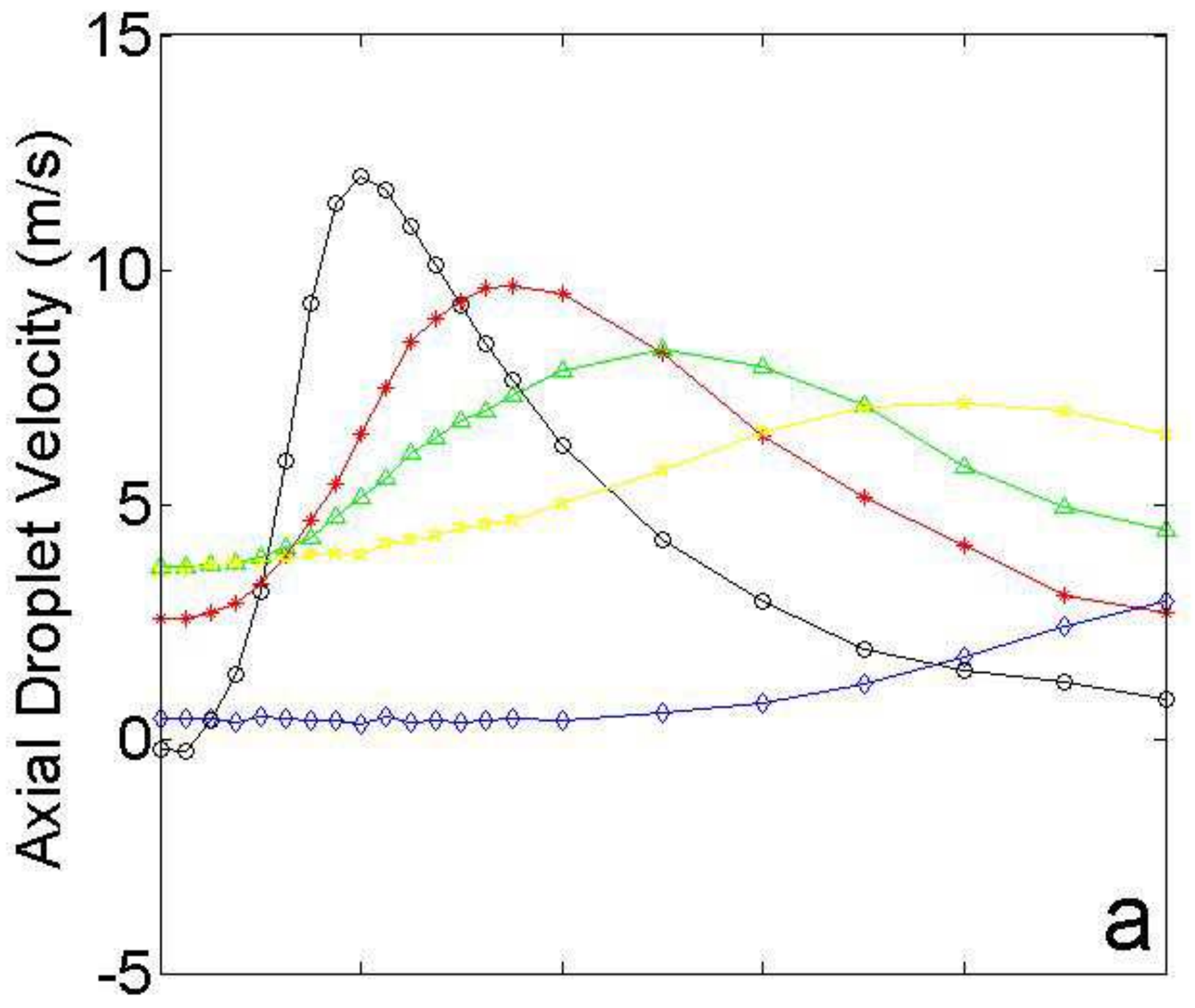




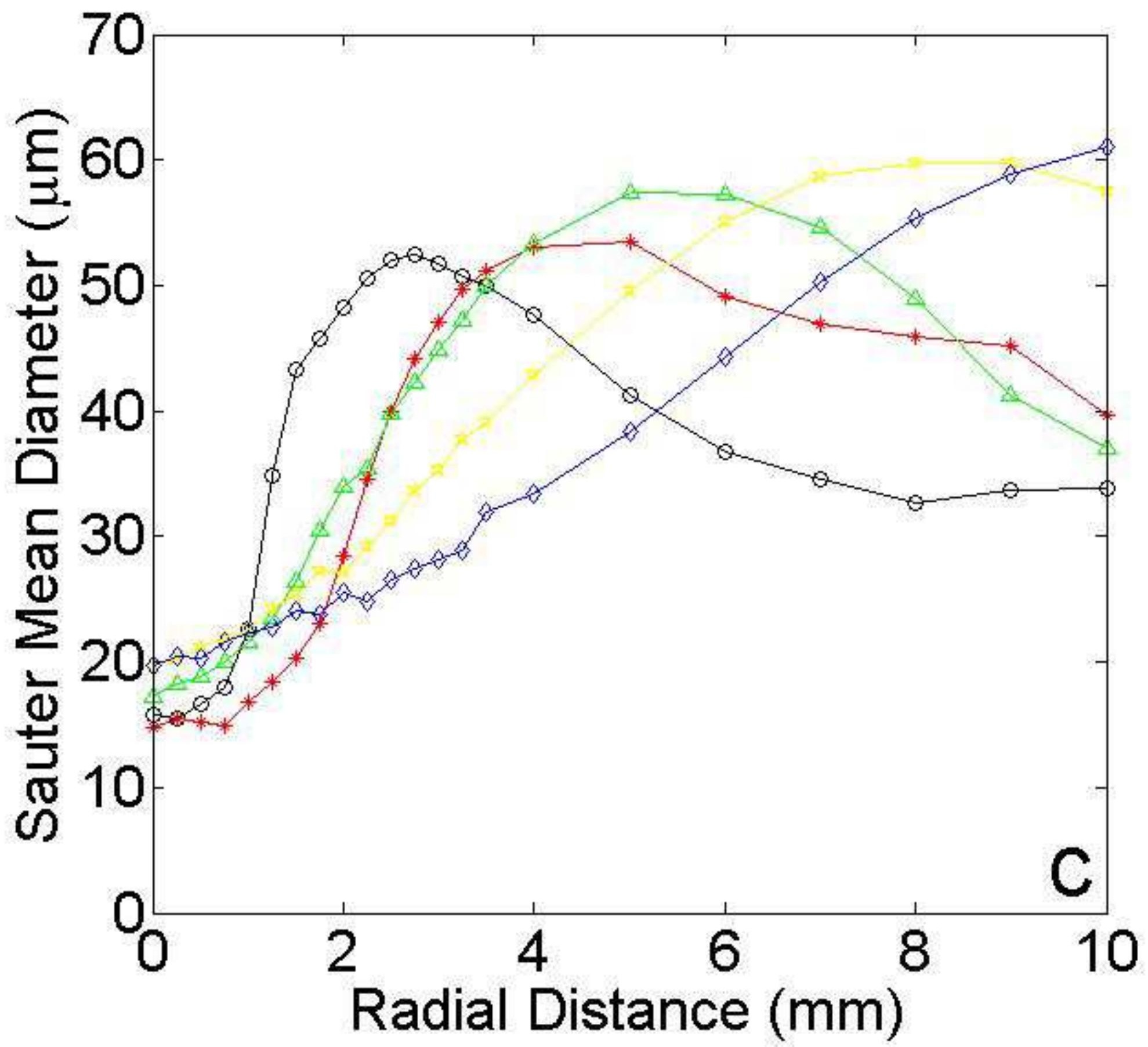




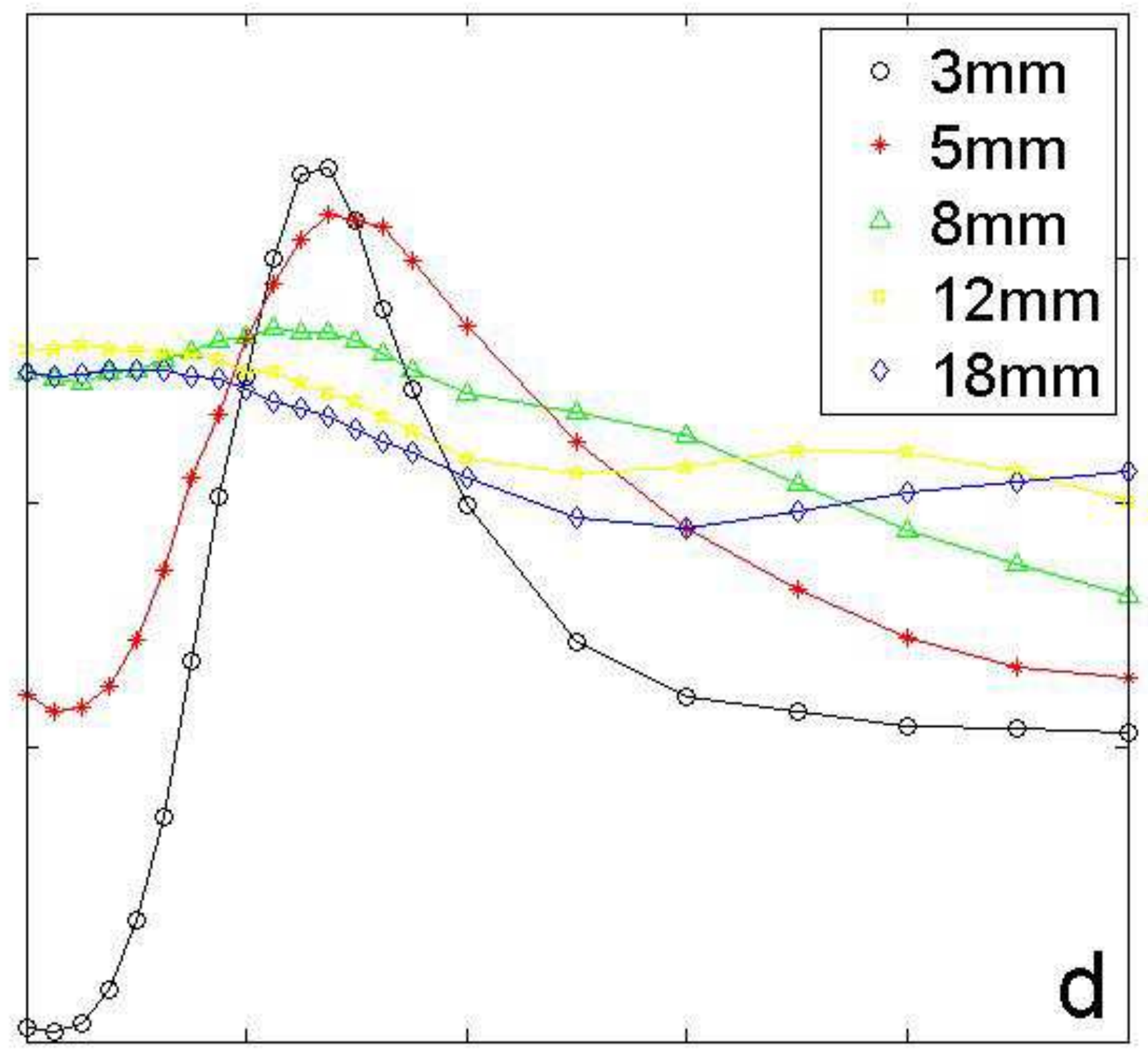




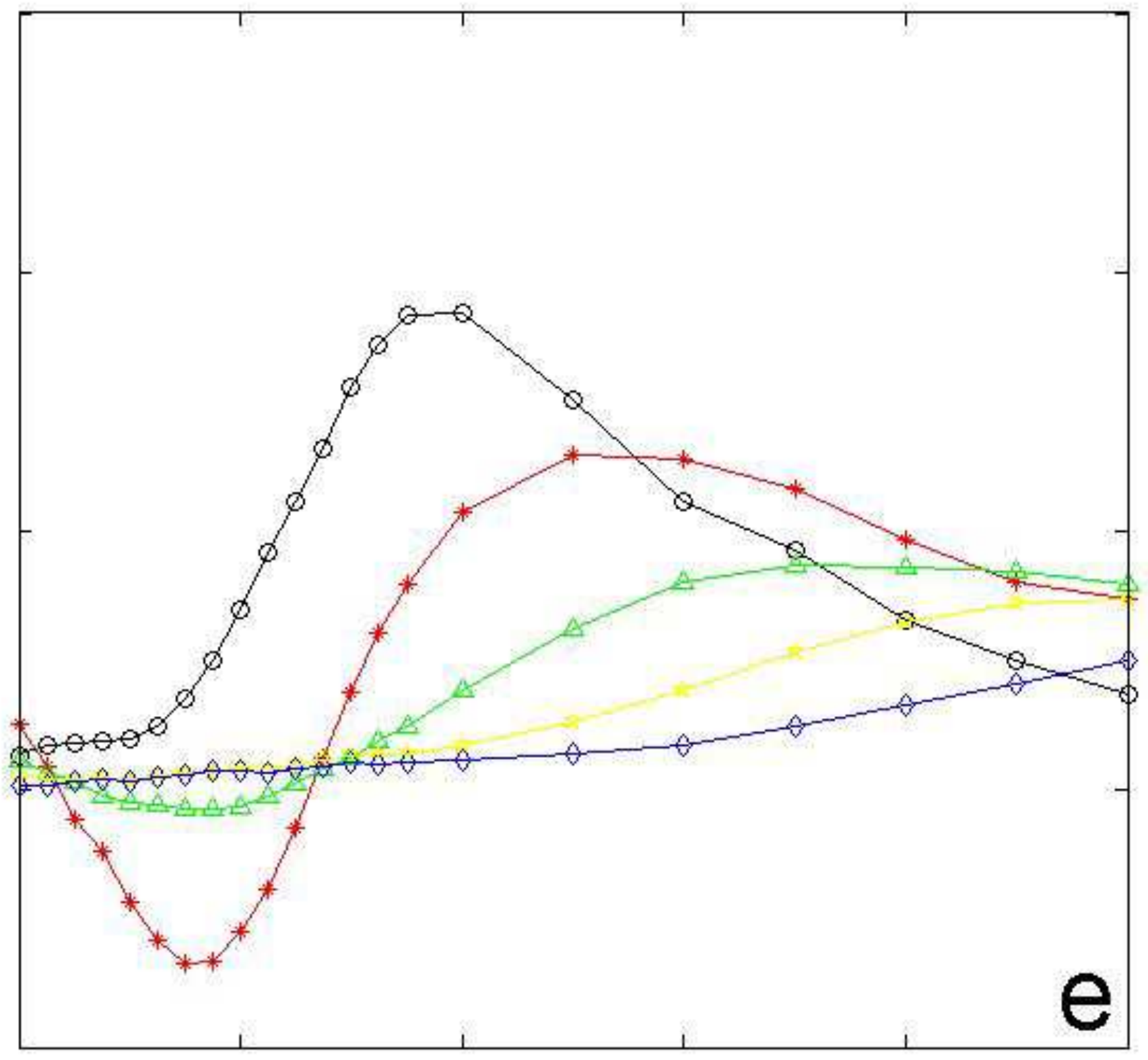




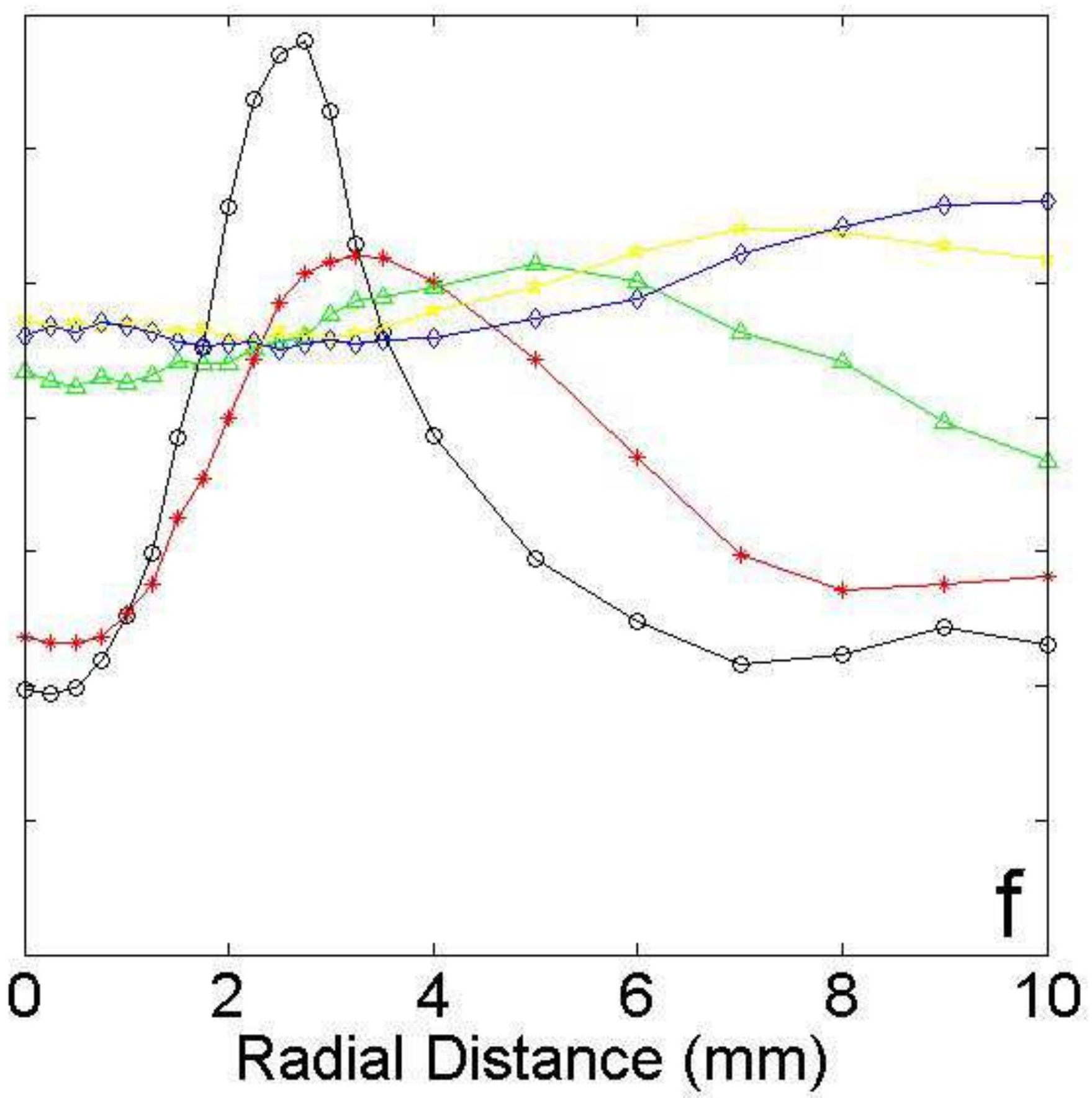




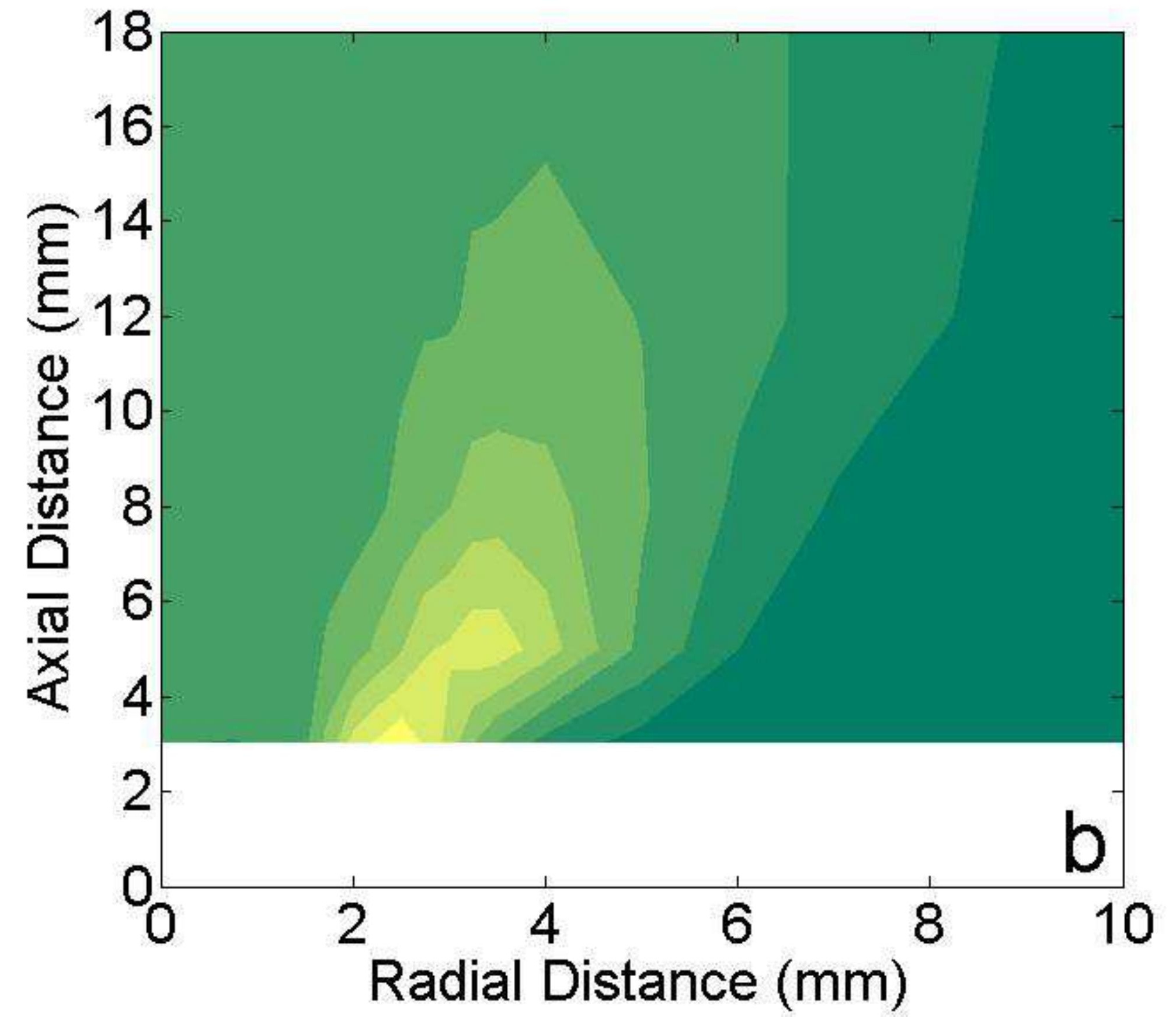




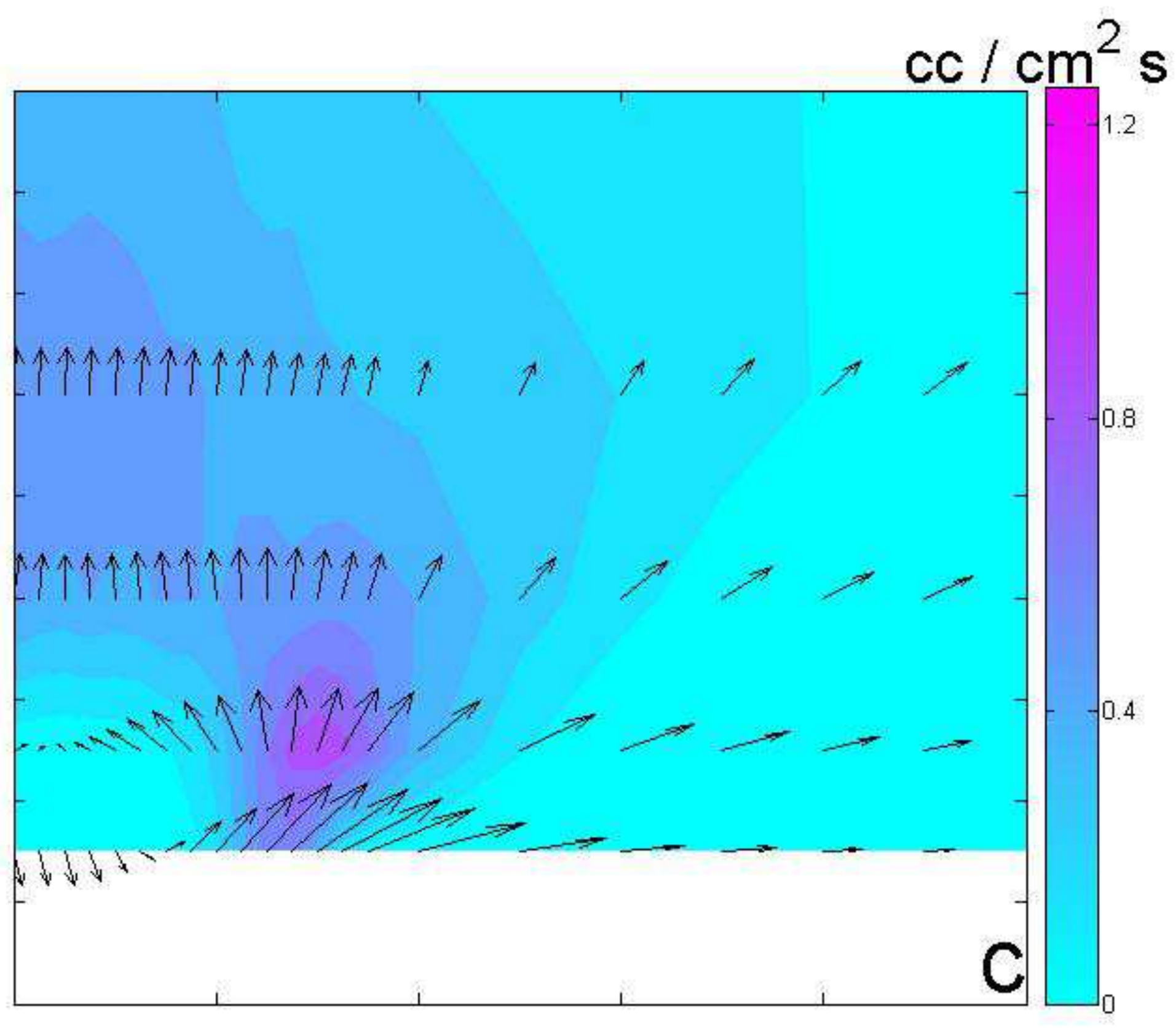


$\# / \mathrm{cm}^{3} \times 10$

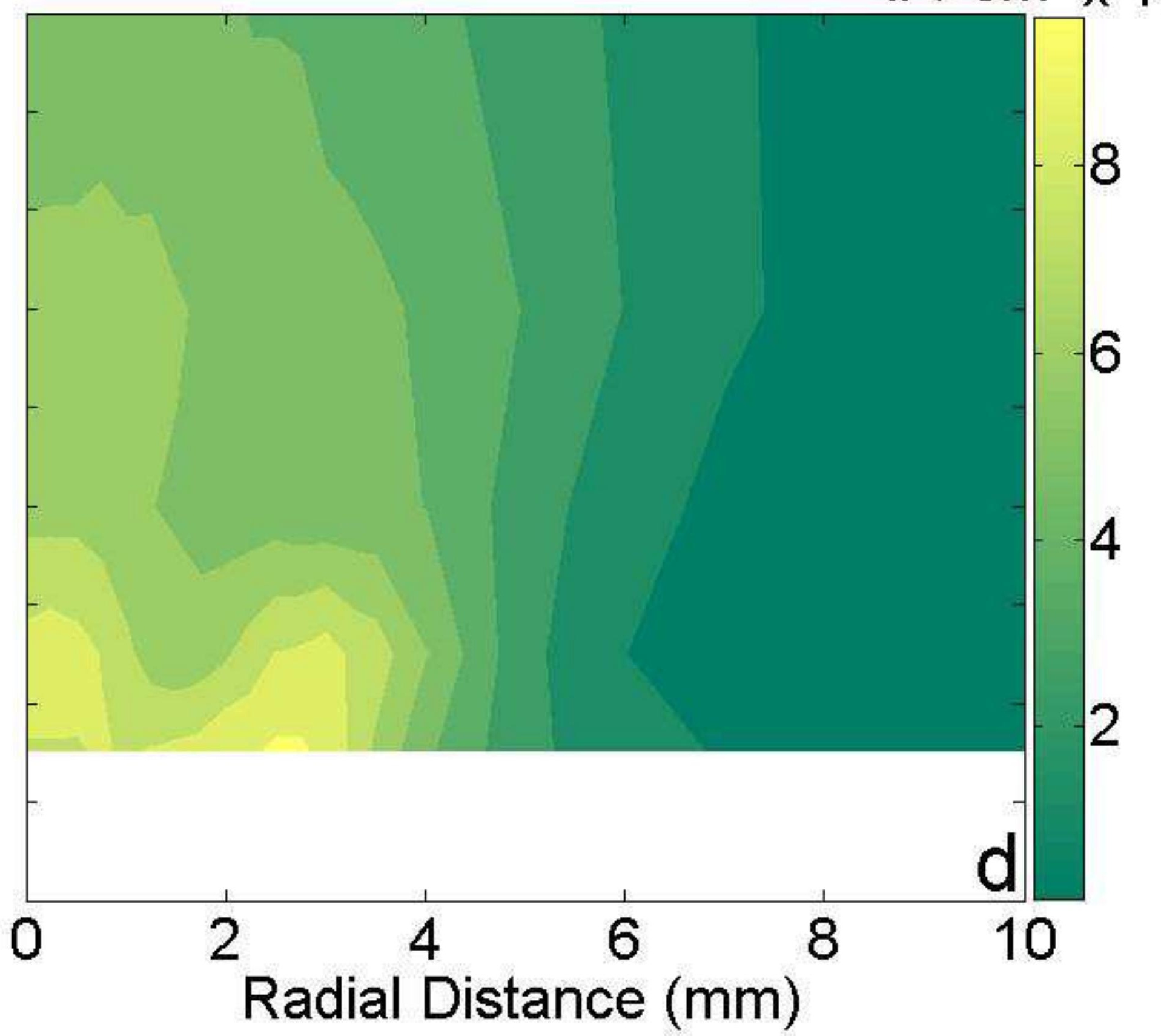



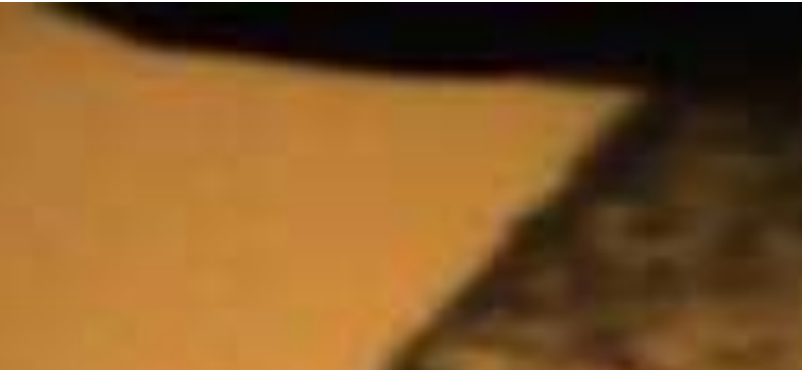


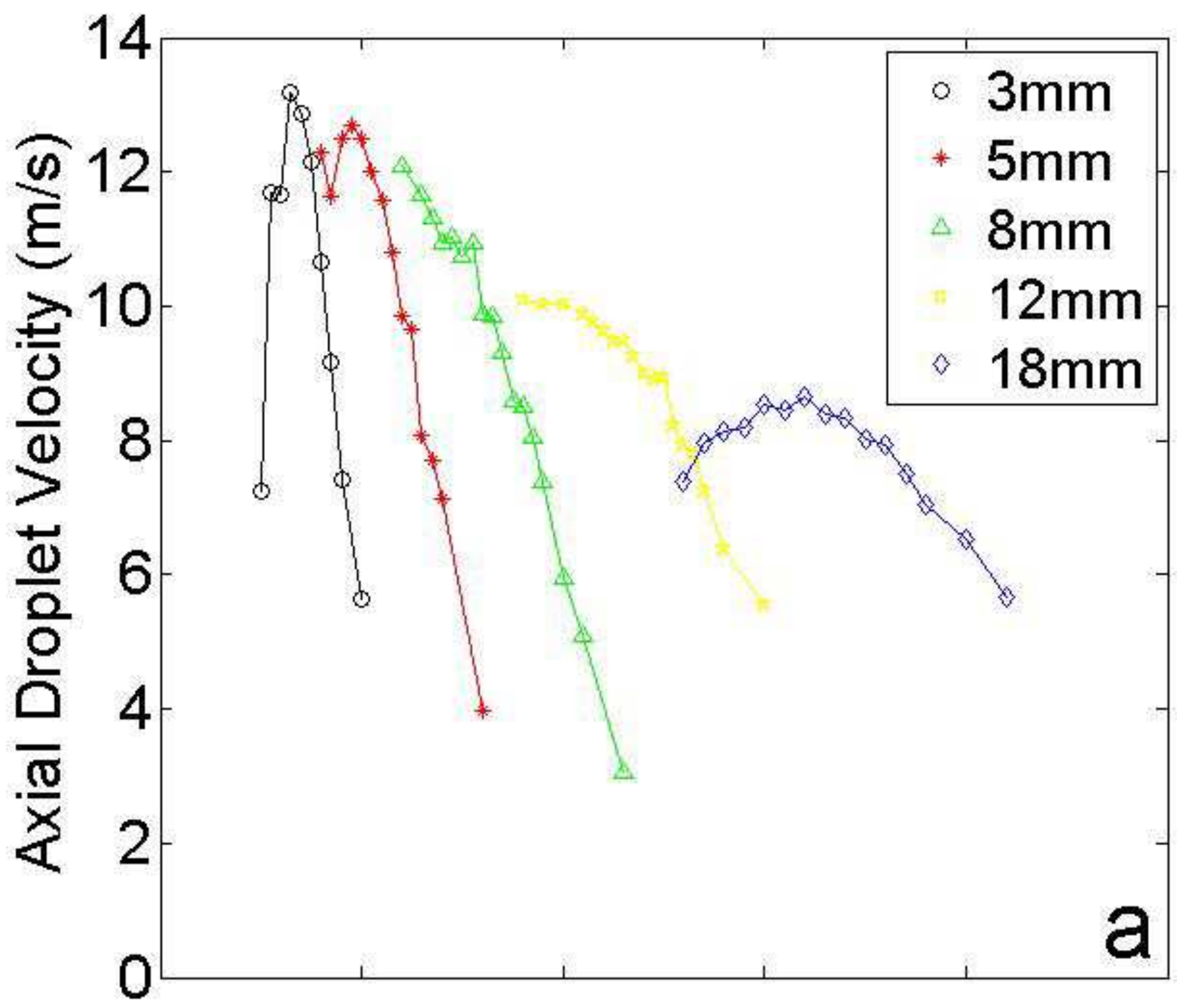




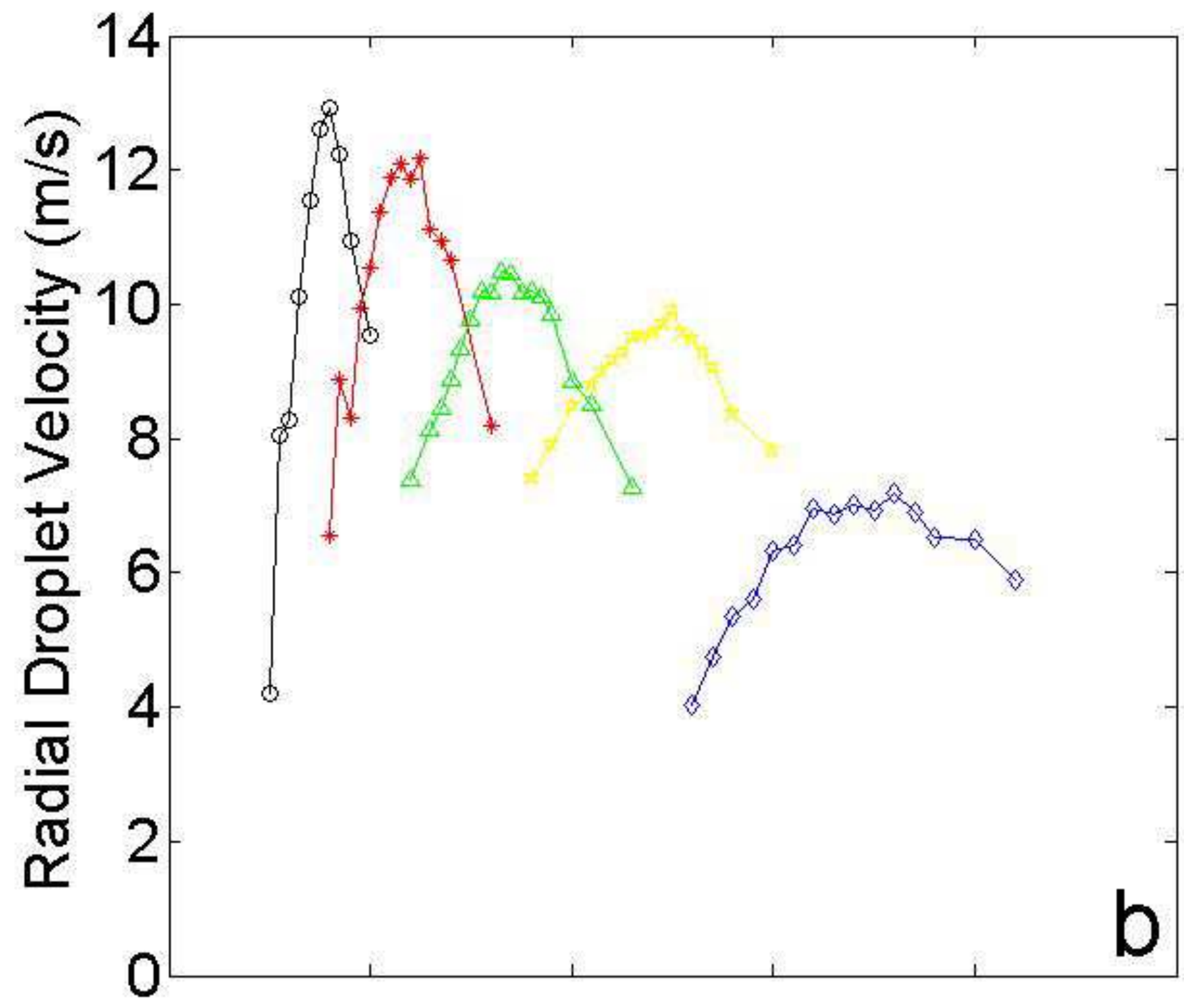




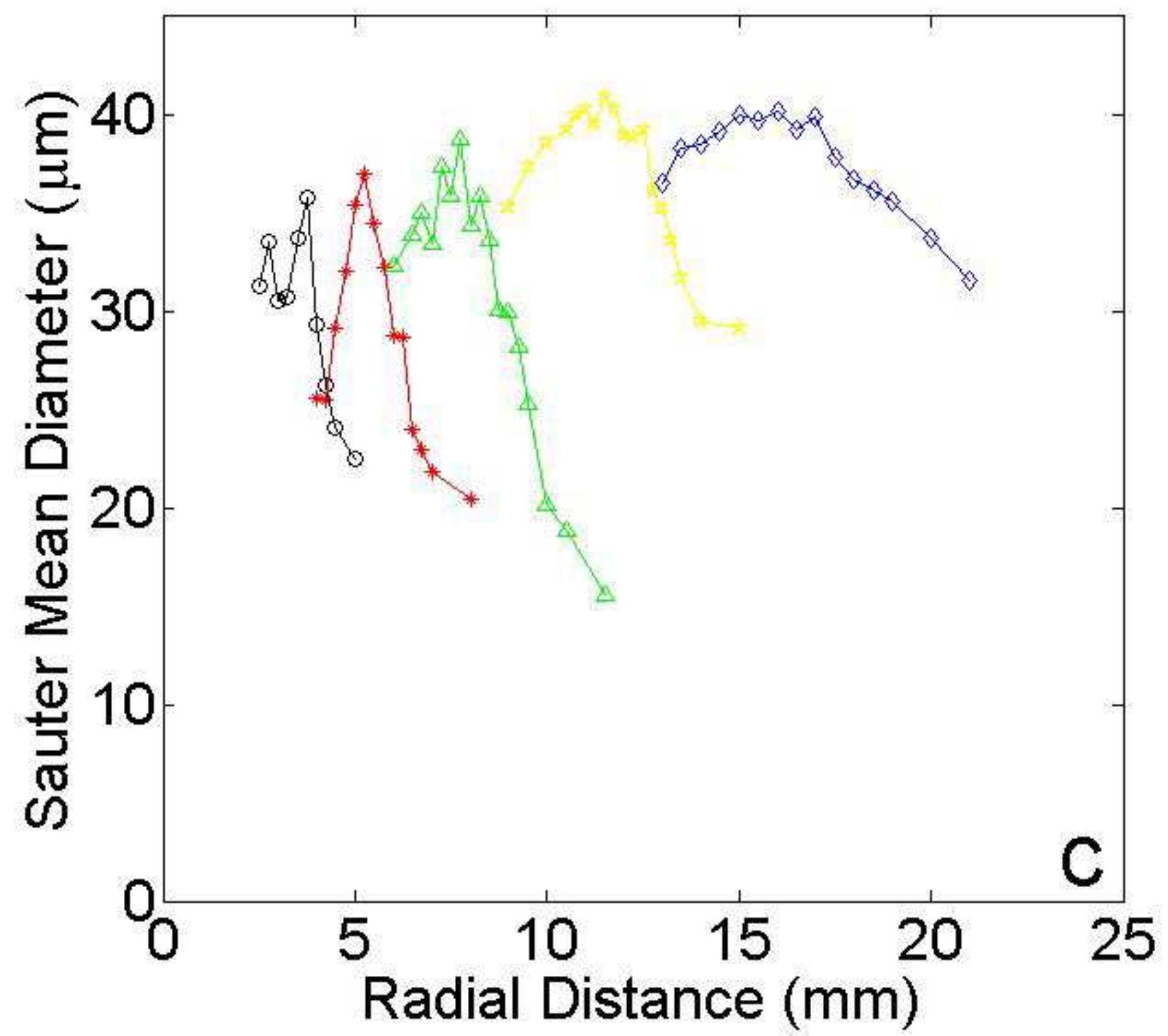




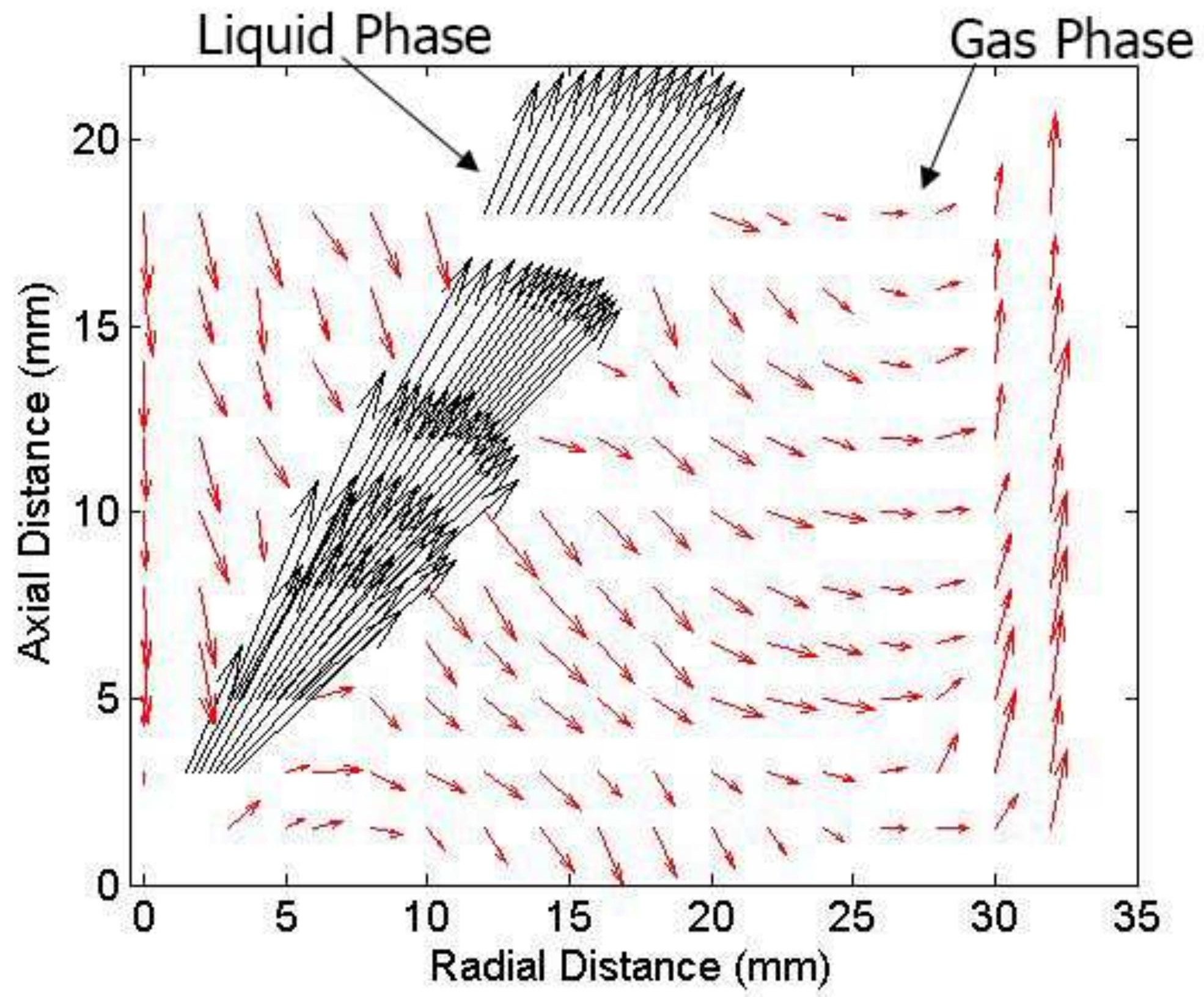




\begin{tabular}{|c|c|c|c|c|c|c|c|}
\hline Case & Fuel & Condition & $\begin{array}{c}\text { Flow rate } \\
(\mathrm{g} / \mathrm{s})\end{array}$ & Oxidizer & $\begin{array}{c}\text { Kinematic } \\
\text { Viscosity } v \\
\left(\mathrm{~mm}^{2} \mathbf{s}^{-1}\right)\end{array}$ & $\begin{array}{c}\text { Surface } \\
\text { Tension } \sigma \\
\left(\mathrm{mN} \mathrm{m}^{-1}\right)\end{array}$ & $\begin{array}{c}\text { Density } \rho \\
\left(\mathrm{kg} \mathrm{m}^{-3}\right)\end{array}$ \\
\hline G30 & \begin{tabular}{|c|}
$30 \%$ \\
glycerol/70 \\
$\%$ water
\end{tabular} & Cold & 0.48 & - & 1.39 & 67.5 & 1057 \\
\hline G30E10 & $\begin{array}{c}30 \% \\
\text { glycerol } / 10 \\
\% \\
\text { ethanol/60 } \\
\% \text { water }\end{array}$ & Cold & 0.5 & - & 1.89 & 44.1 & 1024 \\
\hline G30E10c & $\begin{array}{c}30 \% \\
\text { glycerol } / 10 \\
\% \\
\text { ethanol/60 } \\
\% \text { water }\end{array}$ & $\begin{array}{c}\text { Combustin } \\
\mathrm{g}\end{array}$ & 0.5 & $\begin{array}{c}\mathrm{O}_{2} \\
22.5 \mathrm{LPM} \\
100 \% \text { swirl }\end{array}$ & 1.89 & 44.1 & 1024 \\
\hline
\end{tabular}




\begin{tabular}{|c|c|c|}
\hline & $\begin{array}{c}\mathbf{3 0 \%} \\
\text { glycerol }\end{array}$ & $\begin{array}{c}30 \% \\
\text { glycerol/ } \\
10 \% \\
\text { ethanol }\end{array}$ \\
\hline$C_{\mathrm{D}}$ & 0.4 & 0.42 \\
\hline $\boldsymbol{R e}$ & $5.2 \times 10^{3}$ & $3.9 \times 10^{3}$ \\
\hline We & 0.89 & 1.54 \\
\hline Oh & $12 \times 10^{-3}$ & $20 \times 10^{-3}$ \\
\hline
\end{tabular}

